\title{
Factors Affecting Acceptance of Hospital Information Systems Based on Extended Technology Acceptance Model: A Case Study in Three Paraclinical Departments
}

\author{
${ }^{1}$ Department of Health Information Technology, Urmia University of \\ Medical Sciences, School of Allied Medical Sciences, Urmia, Iran \\ 2 Social Determinants of Health Research Center, Lorestan University \\ of Medical Sciences, Khorramabad, Iran \\ ${ }^{3}$ Department of Management and Health Information Technology, \\ Shaheed Beheshti University of Medical Sciences, School of Allied \\ Medical Sciences, Tehran, Iran
}

Hamed Nadri ${ }^{1}$ Bahlol Rahimi ${ }^{1}$ Hadi Lotfnezhad Afshar ${ }^{1}$ Mahnaz Samadbeik ${ }^{2}$ Ali Garavand ${ }^{3}$

Appl Clin Inform 2018;9:238-247.

\begin{abstract}
Address for correspondence Bahlol Rahimi, PhD, Department of Health Information Technology, Urmia University of Medical Sciences, Nazloo Campus, Sero Road, Urmia, Iran (e-mail: Bahlol.rahimi@gmail.com).
\end{abstract}

\author{
Abstract \\ Keywords \\ - sociotechnical \\ aspects of \\ information \\ technology \\ - adoption \\ - socio-organizational \\ issues \\ - laboratory \\ information systems \\ - radiology information \\ systems
}

Objective Regardless of the acceptance of users, information and communication systems can be considered as a health intervention designed to improve the care delivered to patients. This study aimed to determine the adoption and use of the extended Technology Acceptance Model (TAM2) by the users of hospital information system (HIS) in paraclinical departments including laboratory, radiology, and nutrition and to investigate the key factors of adoption and use of these systems.

Materials and Methods A standard questionnaire was used to collect the data from nearly 253 users of these systems in paraclinical departments of eight university hospitals in two different cities of Iran. A total of 202 questionnaires including valid responses were used in this study (105 in Urmia and 97 in Khorramabad). The data were processed using LISREL and SPSS software and statistical analysis technique was based on the structural equation modeling (SEM).

Results It was found that the original TAM constructs had a significant impact on the staffs' behavioral intention to adopt HIS in paraclinical departments. The results of this study indicated that cognitive instrumental processes (job relevance, output quality, result demonstrability, and perceived ease of use), except for result demonstrability, were significant predictors of intention to use, whereas the result revealed no significant relationship between social influence processes (subjective norm, voluntariness, and image) and the users' behavioral intention to use the system.

Conclusion The results confirmed that several factors in the TAM2 that were important in previous studies were not significant in paraclinical departments and in government-owned hospitals. The users' behavior factors are essential for successful usage of the system and should be considered. It provides valuable information for hospital system providers and policy makers in understanding the adoption challenges as well as practical guidance for the successful implementation of information systems in paraclinical departments. received

December 29, 2017

accepted after revision

February 28, 2018
Copyright (๑) 2018 Schattauer
DOI https://doi.org/ 10.1055/s-0038-1641595. ISSN 1869-0327. 


\section{Background and Significance}

It is widely accepted that the use of information and communications technology (ICT) in the health care sector and especially in hospitals offers not only great potential for improving the quality of services and the efficiency and effectiveness of the personnel, but also for reducing the organizational expenses. ${ }^{1}$ Information and communication systems can be considered as a health intervention designed to improve the care delivered to patients, just like a new treatment. $^{2}$ Unfortunately, in Iran, structural change has been slow in applying information technology (IT), and also, IT is still in traditional structure bears. ${ }^{3}$ Today, new information technologies can be replaced with the old tools quickly by providing more powerful and faster tools for the users. However, this alternative can be successful when its users accept and effectively use it. ${ }^{4,5}$ The hospital information system (HIS) is a powerful information tool that can help hospital managers to correct decision-making process and to increase hospitals' positive functions. ${ }^{6-8}$ The HIS consists of several modules, and any hospital should at least implement the following modules, which must also be integrated with back office and support modules: registration module, medical records module, billing module, and order communication system (OCS) module that involves supporting modules, such as laboratory, radiology, and nutrition. ${ }^{6,8-11}$ Therefore, organizations and developers should understand that the adoption of HIS is critical. ${ }^{12}$ The user's decision to accept or reject the technology depends on several factors. Many of these are intrinsic factors, such as personality traits and cognitive styles. ${ }^{13,14}$ Many of the researchers in their studies have shown a significant relationship between individual differences and acceptance of the technology. ${ }^{15-18}$ Information systems researchers have thus developed more robust scales of how well a technology "fits" with user's tasks and have validated these task-technology fit instruments to show that they repeatedly identify robust effects in the world. The best known of these is the Technology Acceptance Model (TAM) that can be administered by the users of a technology. ${ }^{2}$ The extended TAM (TAM2) have been proven to be quite reliable and robust in predicting user acceptance. Given that nontechnological factors such as human and organizational characteristics have a significant impact on the acceptance of HIS, especially in government hospitals, ${ }^{19,20}$ TAM2 offers theoretical framework for understanding the user's behavior and the adoption of health information systems. ${ }^{21-23}$ So far, many studies have been conducted based on the TAM and their modifications and extensions in clinical departments and in different countries, but in paraclinical departments, there are few studies on the acceptance of HIS based on TAM and TAM2. ${ }^{24-27}$ In addition, the gap between the perceptions of the different occupational groups may be explained by the use of different modules and interdependency of the care staff. ${ }^{28}$

\section{Extended Technology Acceptance Model}

The TAM was proposed based on the theory of reasoned action (TRA) in 1989 by Davis. ${ }^{29}$ It was developed to understand the user acceptance of IT. The TAM decomposes the attitudinal constructs of previous models into two distinct factors, perceived ease of use (PEU) and perceived usefulness (PU). In 2000, TAM2 ( - Fig. 1) was developed on the basis of TAM by Venkatesh and Davis. ${ }^{16}$ Two processes, the social influence processes (subjective norm, voluntariness, and image) and the cognitive instrumental processes (job relevance, output quality, result demonstrability, and PU) were integrated into this model. The two processes were considered to be crucial to the study of user acceptance. Davis et al ${ }^{15}$ developed TAM to explain why the users accept or reject an innovative information system. The TRA, which was introduced by Fishbein and Ajzen, ${ }^{30}$ was intended to be used to explain and predict employee behavior. TAM highlights the influence derived from external variables and internal beliefs and indicates that system usage can be explained on the basis of the PEU and PU. The internalization impact mentioned in both TRA and TAM implies that subjective norms may influence one's intention to use and also PU of a technology; furthermore, it affects one's attitude, subjective norms,

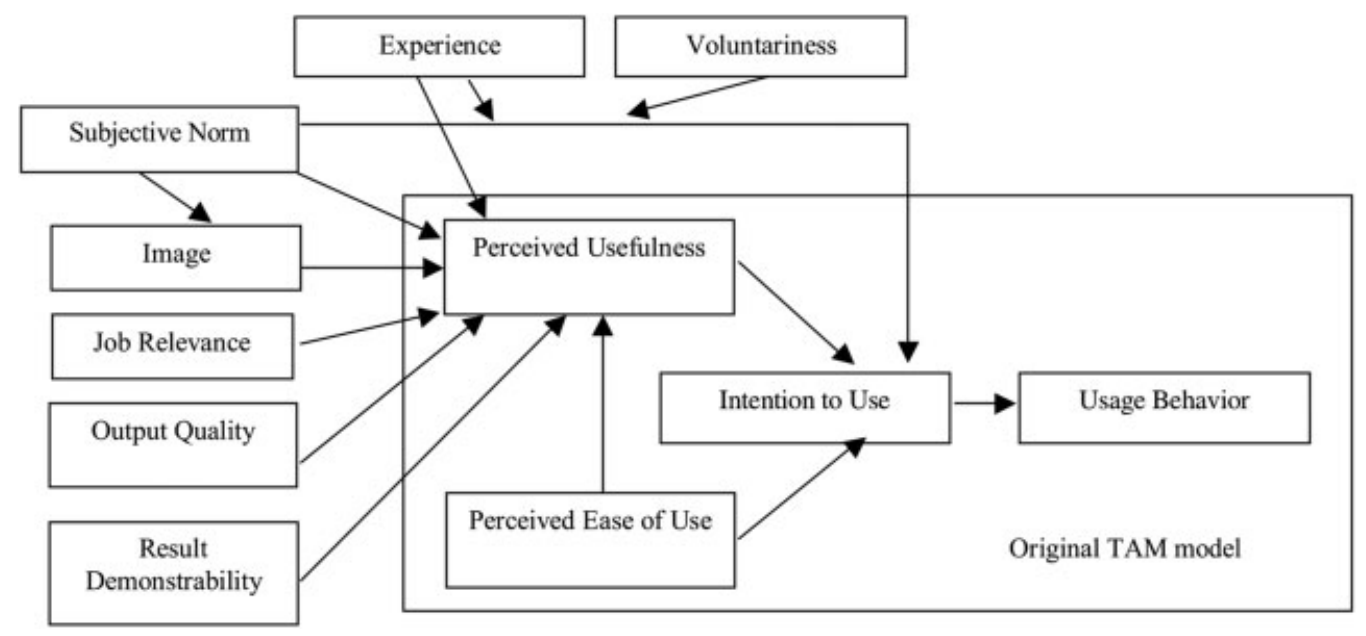

Fig. 1 Extended Technology Acceptance Model (TAM2) (Venkatesh and Davis ${ }^{16}$ ). 
constructs of the TRA model, and PU and PEU in TAM. In both models, an attitude is considered to be influential in behavioral intention. Davis argued that the effect of subjective norms on behavioral intention to use could be ignored; hence, the variables of subjective norms were not considered in TAM. $^{29}$

However, in the extension of TAM, TAM2, Venkatesh and Davis ${ }^{16}$ revisited these variables. In terms of explanatory power, TAM explains only 40 to $50 \%$ of technology acceptance, ${ }^{31}$ whereas TAM2, as pointed out by Davis, reaches $60 \%{ }^{23}$

\section{Objective}

This study aimed to determine the adoption and use of the TAM2 by users of HIS in three paraclinical departments including laboratory, radiology, and nutrition, and also to investigate the key factors of adoption and use of these systems. Structural equation modeling (SEM) was used to analyze the data collected to examine: (1) the relationships between various variables in the TAM2; and (2) the predictability of the TAM2 on participants' acceptance of HISs.

\section{Material and Methods}

\section{Survey Questionnaire}

The data were collected using the standard questionnaire of the TAM2 which was translated into the participants' native language (in Persian) by a professional translator who was well versed in English language and had good knowledge of HISs. The content validity of the questionnaire was evaluated according to the viewpoints of five faculty members of medical informatics and health information management and IT departments of the Urmia University of Medical Sciences and Khorramabad University of Medical Sciences. Then, its reliability was measured and the questionnaire was administered to a sample of 20 persons other than research sample. The Cronbach's $\alpha$ coefficient was used to estimate the reliability of the questions. The Cronbach's $\alpha$ coefficients of the constructs are as follow: familiarity with IT (0.775), intention to use (0.912), PU (0.907), PEU (0.814), subjective norm (0.925), image (0.921), job relevance (0.884), output quality (0.819), result demonstrability (0.717), and voluntariness (0.826). It can be seen from the above measurements that the calculated Cronbach's $\alpha$ values ranged from 0.717 to 0.925 . The questionnaire consisted of 43 questions in the following three parts: (1) demographic data (10 questions), (2) familiarity with IT (6 questions), and (3) questions related to the TAM2 model (27 questions) that included PU, PEU, intention to use, subjective norm, image, job relevance, output quality, result demonstrability, voluntariness, and usage behavioral. Questions related to the model were scored based on the Likert scale from 1 (strongly disagree) to 7 (strongly agree).

\section{Research Population}

This study was an applied, descriptive, and analytic research. The research population consisted of all users using the HISs among paraclinical departments relying on three important laboratory (pathology, microbiology, microbiology, parasitology, toxicology, and so on), radiology, and nutrition departments in Urmia and Khorramabad university hospitals in Iran; each city had four university hospitals. A total of 270 users were identified as being eligible to be included in this study. The research population consisted of the staffs of the nutrition, laboratory, and radiology departments as well as the secretaries of these departments.

\section{Data Collection}

Initial contact of the researchers with users was made to provide information, in a form of information sheet, including the definition of HISs and the purpose of the study. The questionnaires were personally distributed by the researchers in August 2017. Respondents were also made aware of their rights to withdraw participation at any time during the study.

\section{Data Analyses}

SEM is a statistical method that combines factor analysis and path analysis, provides theory construction, and analyses the relationships between the various variables, therefore SEM was applied in this study to examine the research model and hypotheses. SEM is a widely accepted paradigm to gauge the validity of theories with empirical data. The LISREL method, a statistical analysis technique based on the SEM, was used to test and validate the proposed model and the relationships between the hypothesized constructs. Data were analyzed using LISREL V8.80, a statistical software, to determine the fit of the model and SPSS V16 with a significant level $(p<0.05)$ to calculate descriptive statistics (analysis of demographic data). Analytical statistics (Pearson's correlation coefficient, regression, independent $t$-test, and analysis of variance [ANOVA]) were used to analyze the results.

\section{Hypotheses}

Ten hypotheses were investigated according to - Fig. 2, based on the constructs of TAM2 developed by Venkatesh and David. Subjective norms influence one's intention to use a system, whether one likes to do it or not. If people important or powerful enough to this person think that using the system is necessary, this person will use it as normally expected. Taylor and Peter found that subjective norms have significant influence on behavioral intention. ${ }^{32}$ The TAM2 indicates that subjective norms influence the intention to use through PU and calls it as an internalization process.

Practicing the behaviors expected by group norms, individuals can "gain support of the entire group and society, and the performance of the entire group can also be enhanced." 33 Users can enhance their work efficiency if they are clear about their job-related knowledge. It can be inferred that job relevance has direct influence on PU. When the users consider a system to be contributive to the execution of tasks, they will perceive an improvement of work efficiency. Such perception is perceived output quality. Previous studies have empirically indicated that perceived output quality has a positive relationship with PU. ${ }^{34-36}$ 


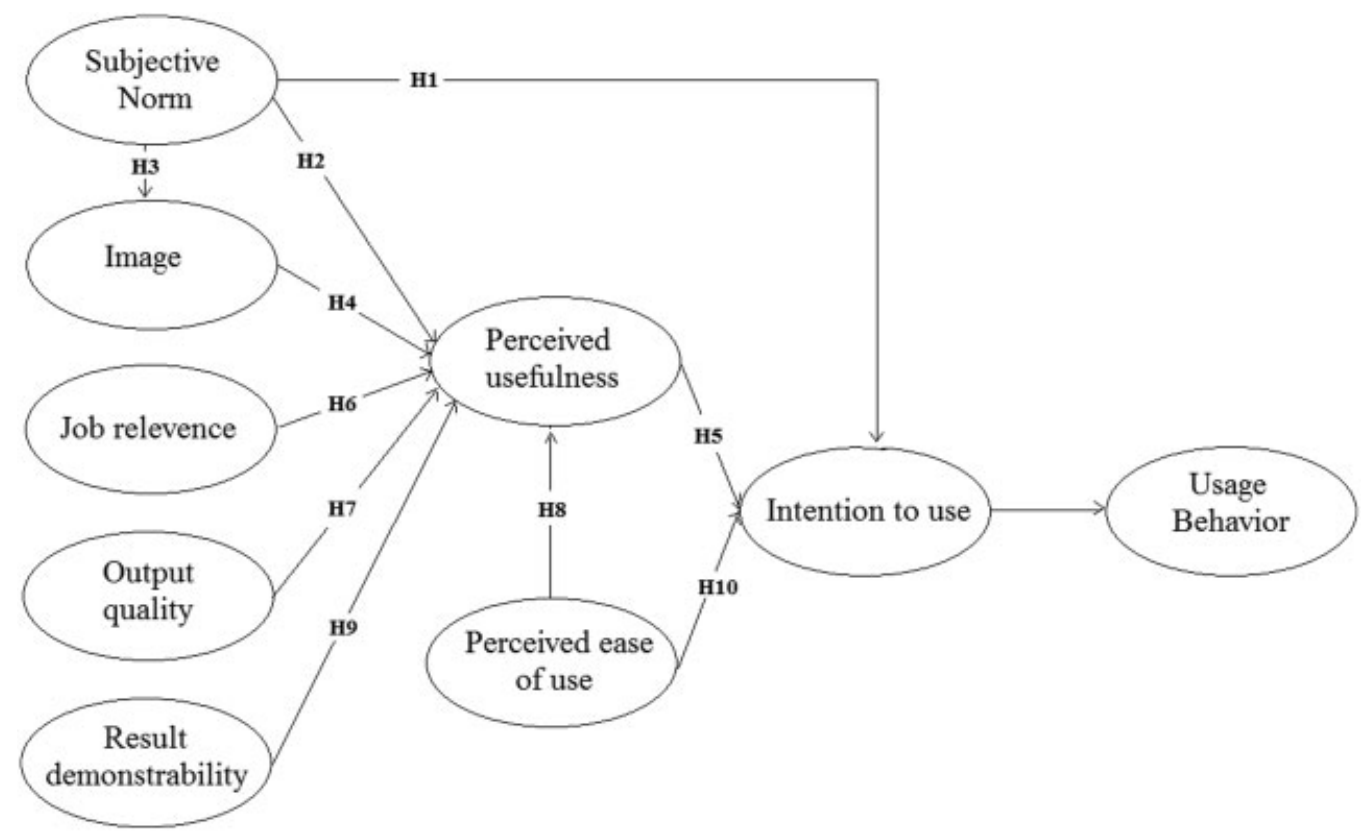

Fig. 2 Research frame work.

Most of the respondents in our survey have used the system for more than 6 months. In this study, the effect of experience is not considered; therefore, the "experience" is excluded from our model. In addition, most of users are forced to use system. Therefore, the moderator "voluntariness" is excluded from our model. On the basis of the proposed hypotheses, the research framework can be constructed as shown in - Fig. 2.

\section{Results}

In this study, 253 questionnaires were distributed, of which finally 202 were received completed for further analysis (overall response rate, $80 \%$ ). The total number of questionnaires returned was 105 from Urmia and 97 from Khorramabad.

\section{Demographic Characteristics of Population}

As shown in -Table 1, the collected sample comprises $(n=88)$ of $39.6 \%$ male and $(n=122) 60.4 \%$ female, implying that most of the population is female. Most of the participants were in the 26 to $30(n=51,25.2 \%)$ and 36 to 40 age groups $(n=46,22.8 \%)$ and also $(n=143) 70.8 \%$ participants have had bachelor's degree. Moreover, 52\% participants in the HISs have not been trained and the rest have been trained. With regard to the usage of the system, it is found that the users with more than 3 years' experiences of using the system constitute the main proportion (56.3\%). This reveals that most of the participants have sufficient experience in using the systems. About 29.7\% participants were contractual labors, and $29.2 \%$ participants were permanent labors. Moreover, 65.3\% participants worked in the hospital laboratory department, followed by $28.7 \%$ in the radiology department and the rest are in the nutrition department.

\section{Relationship between the Demographic Characteristics and Latent Variables}

-Table 2 shows the relationship between the demographic variables and latent variables of this study. In the most cases, the relationship between variables was not significant ( $p$ value $>0.05$ ).

According to - Table 2, there are significant relationships between employment status and gender factors and intention to use. Age, experience of using the system, gender, and training factors affect the PU. Training is the only factor affecting the PEU. Gender and training factors affect the job relevance. Gender is the only factor affecting the quality output.

According to - Table 3 , it was found that there is a significant correlation between work experience and PU of respondents $(p<0.01)$. There was a significant correlation between familiarity with IT and all variables, except for intention to use. Moreover, it was found that there is significant correlation between training time and PU and quality output.

\section{Hypothesis Testing}

With an adequate measurement model, SEM was conducted to examine the hypothetical relationships between aforementioned constructs. The first step in model testing is to estimate the goodness-of-fit of the research model. The indices recommended for evaluating the overall model fitness are those suggested from previous studies. ${ }^{37-39}$ Note that the goodness-of-fit of our proposed model is acceptable as well (chi-square [210] $=528.73$; normed fit index [NFI] $=0.91$; non-NFI $[\mathrm{NNFI}]=0.93$; comparative fit index $[\mathrm{CFI}]$ $=0.94$; incremental fit index $[\mathrm{IFI}]=0.94$; goodness-of-fit index $[\mathrm{GFI}]=0.81$; root mean square error of approximation $[$ RMSEA $]=0.08$ ). The chi-square test provides a statistical test for the null hypothesis that the model fits the data. 
Table 1 Demographic characteristics of staffs participating in the study

\begin{tabular}{|c|c|c|c|c|c|}
\hline Item & Category & $\begin{array}{l}\text { Numbers and } \\
\text { percentage } \\
(\%)\end{array}$ & Item & Category & $\begin{array}{l}\text { Numbers and } \\
\text { percentage (\%) }\end{array}$ \\
\hline \multirow[t]{2}{*}{ Gender } & Male & $80(39.6)$ & \multirow{7}{*}{$\begin{array}{l}\text { Experience } \\
\text { of using system }\end{array}$} & \multirow{2}{*}{$\begin{array}{l}\text { No more than } 6 \\
\text { mo }\end{array}$} & \multirow[t]{2}{*}{$21(10.4)$} \\
\hline & Female & $122(60.4)$ & & & \\
\hline \multirow[t]{6}{*}{ Age } & Under 25 y old & $27(13.4)$ & & $6 \mathrm{mo}-1 \mathrm{y}$ & $11(5.4)$ \\
\hline & $26-30$ y old & $51(25.2)$ & & $1-2 y$ & $24(11.9)$ \\
\hline & $31-35$ y old & $38(18.8)$ & & $2-3 y$ & $26(12.9)$ \\
\hline & $36-40$ y old & $46(22.8)$ & & \multirow[t]{2}{*}{ More than $3 \mathrm{y}$} & \multirow[t]{2}{*}{$120(59.4)$} \\
\hline & $41-45$ y old & $27(13.4)$ & & & \\
\hline & Over 46 y old & $13(6.4)$ & \multirow{6}{*}{$\begin{array}{l}\text { Employment } \\
\text { status }\end{array}$} & Permanent & $59(29.2)$ \\
\hline \multirow[t]{6}{*}{ Education degree } & Associate & $33(16.3)$ & & Temporary & $32(15.8)$ \\
\hline & Bachelor & $143(70.8)$ & & Contractual & $60(29.7)$ \\
\hline & Master & 22 (10.9) & & Corporative & $6(3.0)$ \\
\hline & Doctoral & $1(0.5)$ & & \multirow{2}{*}{$\begin{array}{l}\text { Human resource } \\
\text { program }\end{array}$} & \multirow[t]{2}{*}{$45(22.3)$} \\
\hline & \multirow{2}{*}{$\begin{array}{l}\text { General } \\
\text { Practitioner }\end{array}$} & \multirow[t]{2}{*}{$3(1.5)$} & & & \\
\hline & & & \multirow[t]{3}{*}{ Departments } & Laboratory & $132(65.3)$ \\
\hline \multirow[t]{2}{*}{ Training } & Trained & $97(48.0)$ & & Radiology & $58(28.7)$ \\
\hline & Untrained & $105(52.0)$ & & Nutrition & $12(6.0)$ \\
\hline
\end{tabular}

Note: The numerical figure is numbers, and the parenthesized value denotes the percentage

Bagozzi and Yi suggested a chi-square per degrees of freedom instead. ${ }^{39}$ All of the fit indices indicate that the structural model has a good fit ( - Table 4 ).

The second step in model testing is to examine the path significance of each hypothesized association in the research mode. The structural model was developed to identify the relationships between the constructs in the research model. Through LISREL test of the theoretical model, 10 hypotheses were proposed. In this study, the relationship between dependent and independent variables was tested by estimating the standardized parameter and the $t$-values of the hypotheses are shown in -Fig. 3. The LISREL results for the structural model are listed in -Table 5. The results show that the relationships between subjective norm and image $(t=5.43, p<0.05)$, job relevance and PU $(t=4.48$, $p<0.05)$, output quality and $\mathrm{PU}(t=3.42, p<0.05)$, PU and intention to use $(t=3.89, p<0.05)$, PEU and PU $(t=3.35$, $p<0.05)$, and PEU and intention to use $(t=1.97, p<0.05)$ were significant. Thus, H3, H5, H6, H7, H8, and H10 were confirmed. However, the relationships between subjective norm and intention to use $(t=0.5, p>0.05)$, subjective norm and $\mathrm{PU}(t=-0.18, p>0.05)$, image and PU

Table 2 Investigation of the relationship between age, gender, degree, and latent variables

\begin{tabular}{|l|l|l|l|l|l|l|}
\hline Variables & Age & $\begin{array}{l}\text { Education } \\
\text { degree }\end{array}$ & $\begin{array}{l}\text { Employment } \\
\text { Status }\end{array}$ & $\begin{array}{l}\text { Experience } \\
\text { of using } \\
\text { system }\end{array}$ & Gender & Training \\
\cline { 2 - 7 } & $\begin{array}{l}\text { ANOVA } \\
(p \text {-Value) }\end{array}$ & $\begin{array}{l}\text { ANOVA } \\
(p \text {-Value) }\end{array}$ & $\begin{array}{l}\text { ANOVA } \\
(p \text {-Value) }\end{array}$ & $\begin{array}{l}\text { ANOVA } \\
(p \text {-Value) }\end{array}$ & $\begin{array}{l}\text { Independent } \\
\text { sample } t \text {-test } \\
(p \text {-Value) }\end{array}$ & $\begin{array}{l}\text { Independent } \\
\text { sample } t \text {-test } \\
(p \text {-Value) }\end{array}$ \\
\hline Intention to use & 0.15 & 0.14 & 0.02 & 0.19 & 0.64 & 0.03 \\
\hline Perceived usefulness & 0.02 & 0.92 & 0.24 & 0.01 & 0.04 & 0.00 \\
\hline Perceived ease of use & 0.79 & 0.47 & 0.10 & 0.39 & 0.68 & 0.04 \\
\hline Subjective norm & 0.09 & 0.38 & 0.46 & 0.50 & 0.28 & 0.50 \\
\hline Image & 0.35 & 0.30 & 0.48 & 0.54 & 0.21 & 0.99 \\
\hline Job relevance & 0.55 & 0.63 & 0.60 & 0.55 & 0.03 & 0.01 \\
\hline Quality output & 0.34 & 0.76 & 0.61 & 0.77 & 0.02 & 0.18 \\
\hline Result demonstrability & 0.71 & 0.28 & 0.83 & 0.54 & 0.36 & 0.10 \\
\hline
\end{tabular}

Abbreviation: ANOVA, analysis of variance. 
Table 3 The correlations between the mediator variables and latent variables

\begin{tabular}{|l|l|l|l|}
\hline Variables & $\begin{array}{l}\text { Work } \\
\text { experience } \\
(p \text {-Value })\end{array}$ & $\begin{array}{l}\text { Familiarity } \\
\text { with IT } \\
(p \text {-Value })\end{array}$ & $\begin{array}{l}\text { Training } \\
\text { time } \\
(p \text {-Value })\end{array}$ \\
\hline Intention to use & 0.17 & 0.70 & 0.12 \\
\hline $\begin{array}{l}\text { Perceived } \\
\text { usefulness }\end{array}$ & 0.008 & 0.01 & 0.023 \\
\hline $\begin{array}{l}\text { Perceived ease } \\
\text { of use }\end{array}$ & 0.86 & 0.003 & 0.98 \\
\hline Subjective norm & 0.87 & 0.04 & 0.88 \\
\hline Image & 0.85 & 0.001 & 0.83 \\
\hline Job relevance & 0.68 & 0.032 & 0.65 \\
\hline Quality output & 0.68 & 0.011 & 0.013 \\
\hline $\begin{array}{l}\text { Result } \\
\text { demonstrability }\end{array}$ & 0.44 & 0.032 & 0.15 \\
\hline
\end{tabular}

Abbreviation: IT, information technology.

$(t=0.33, p>0.05)$, and result demonstrability and PU $(t=-0.35, p>0.05)$ were insignificant and $\mathrm{H} 1, \mathrm{H} 2, \mathrm{H} 4$, and $\mathrm{H} 9$ were rejected in this study.

\section{Discussion}

In this study, it was tried to explore how variables affect staffs' behavior of intention to use the HISs in paraclinical departments. The empirical findings have provided insight into the TAM2 constructs such as PU, PEU, subjective norm, image, output quality, job relevance, result demonstrability, experience, and voluntariness influencing the adoption of the system. The study provides empirical support for the hypotheses proposed in relation to PU, PEU, output quality, and job relevance in the system adoption and usage. In addition, the results of this study showed that the numbers of the mediator and demographic variables have direct and indirect effects on the adoption and use of the system. Several important mediator variables, such as training (also training time), experience of using system, work experience, and familiarity with IT, influence the adoption of the system and these should be considered in the system acceptance model. Our findings are consistent with several previous studies and are inconsistent with several other studies. ${ }^{21}$ This can be due to many reasons, such as insensitivity of paraclinical departments rather than clinical departments, not fitting of information system with paraclinical departments, lack of understanding of the benefits of the system, and lack of clear understanding of the needs of users of HISs in paraclinical departments.

The empirical findings completely confirmed the original TAM constructs such as PU, PEU, and intention to use influencing the adoption of the system. These findings are consistent with the following research results. Several studies $^{22,40-42}$ indicated that physicians', staffs', and nurses' PEU and PU on HISs significantly impact the system acceptance and intention to use. Ologeanu-Taddei et $\mathrm{al}^{28}$ administrated a study based on the main concepts of TAM to examine the PU, the PEU, and the perceived behavioral control of a HIS for the care staff, and the results indicated that the different occupational groups had a different perceptions of the TAM constructions. As an example, half of the medical secretaries, unlike the anesthesiologists, surgeons, and physicians, think that the use of HIS is easy. Medical secretaries also reported the highest rate of perceived behavioral control and a high rate of PU. Pharmacists reported the highest rate of PU but a low rate of perceived behavioral control. The results of a study by Asua et al and Tavakoli et al ${ }^{43,44}$ show that the original TAM was good at predicting intention to use the telemonitoring and electronic medical record (EMR) systems by nurses, general practitioners, and pediatricians. Therefore, according to our findings and other studies, the original TAM constructions have significant impact on staffs' behavioral intention to use HISs technology in both clinical and paraclinical departments. In addition, by improving users' PEU and PU of the systems, we can enhance the intention to use of the system.

The TAM2 has several external variables that have been approved in most studies on the acceptance of health technologies. In our study, several important variables in the TAM2 were not approved. The subjective norm is an important variable that has been confirmed in most studies especially in clinical systems and other technologies, ${ }^{21}$ but was not supported in this study. However, the subjective norm is an important determinant of image, and there was a direct and positive relationship between the variables of subjective norm and image ( $t$-value $=5.43, p<0.01$ ), as a result, this finding is consistent with findings of Venkatesh

Table 4 The items tested for overall model fit

\begin{tabular}{|c|c|c|c|}
\hline Item & Ideal results & Results & Fit status \\
\hline Chi-square/degrees of freedom (normed chi-square) & $\leq 3$ & 2.5 & $\sqrt{ }$ \\
\hline NFI (normed fit index) & $\geq 0.9$ & 0.91 & $\sqrt{ }$ \\
\hline NNFI (nonnormed fit index) & $\geq 0.9$ & 0.93 & $\sqrt{ }$ \\
\hline CFI (comparative fit index) & $\geq 0.9$ & 0.94 & $\sqrt{ }$ \\
\hline GFI (goodness-of-fit index) & $\geq 0.8$ & 0.81 & $\sqrt{ }$ \\
\hline IFI (Incremental fit index) & $\geq 0.9$ & 0.94 & $\sqrt{ }$ \\
\hline RMSEA (root mean square error of approximation) & $<0.1$ & 0.08 & $\sqrt{ }$ \\
\hline
\end{tabular}




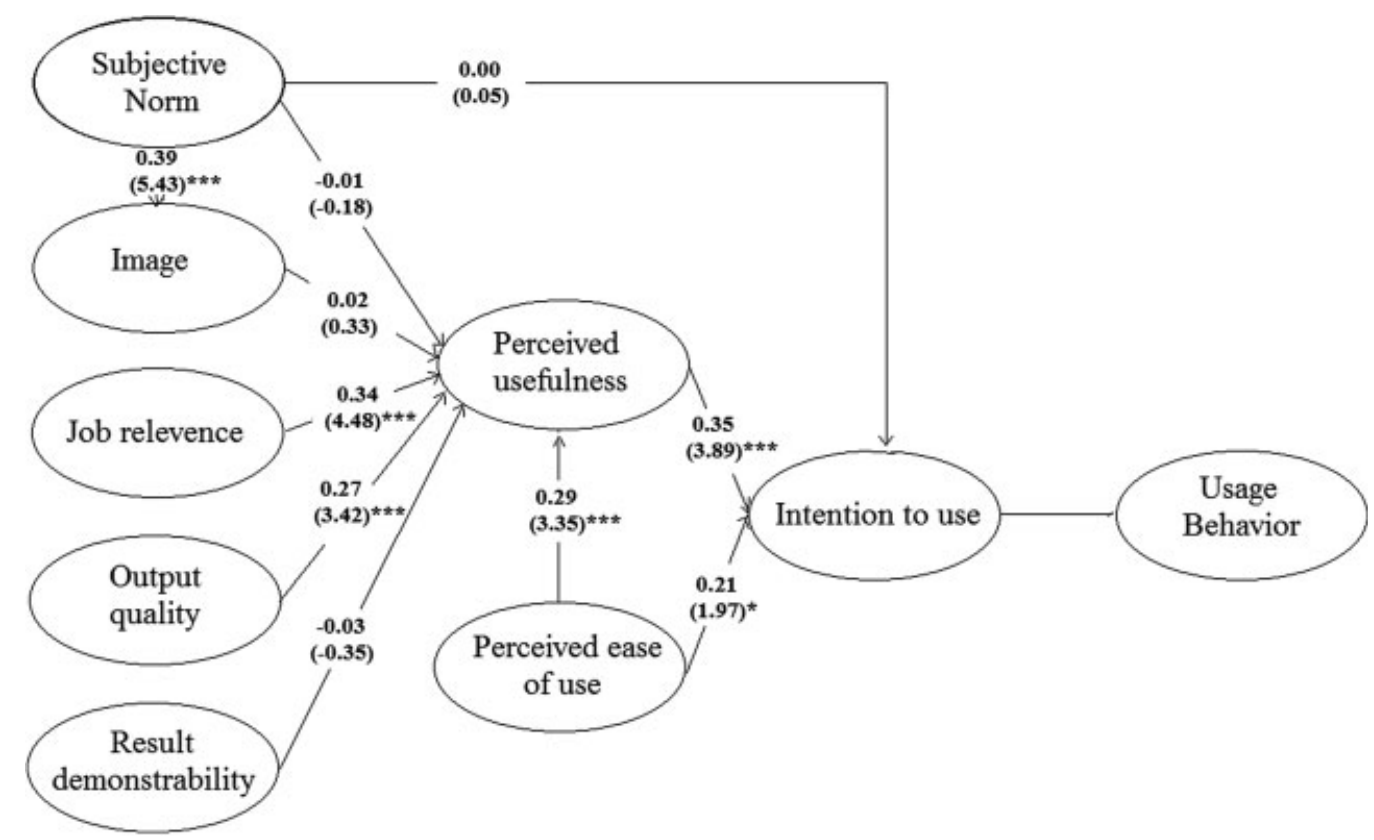

Fig. 3 Path coefficients and relationships of the variables. The numerical figure is standardized parameter estimate, and the parenthesized value is $t$-value. ${ }^{*}$ Denotes $t$-value $>1.96, p<0.05 ;{ }^{* *}$ Denotes $t$-value $>2.58, p<0.01$; ${ }^{* * *}$ Denotes $t$-value $>3.29, p<0.001$.

and Davis that stated: "the effect of subjective norm on image was significant at all points of measurement." ${ }^{16}$ In addition, the correlation between image and PU is rejected ( $t$-value $=0.33, p>0.05$ ). Furthermore, result demonstrability also had no correlation with PU. Yu et $\mathrm{al}^{45}$ indicated that PU, PEU, and familiarity with IT had significant positive impact, whereas image had significant negative impact on caregivers' intention to use health IT applications. PEU and subjective norm also determined the PU. The other demographic factors (including age and work experience) did not have any significant impact on the acceptance of a health IT application. Huang's ${ }^{46}$ study showed that the PU, PEU, and subjective norms influence the behavioral intentions of using telecare. The results indicated that PU, PEU, and subjective norm had significant impact on a professional's intention to use an adverse event reporting system. Among

Table 5 Test of relationships between constructs

\begin{tabular}{|c|c|c|c|}
\hline & Hypotheses & Estimated values & Test results \\
\hline $\mathrm{H} 1$ & $\begin{array}{l}\text { Users' "subjective norm" for using the system has } \\
\text { positive influence on "intention to use" }\end{array}$ & $0.00(0.05)$ & Unsupported \\
\hline $\mathrm{H} 2$ & $\begin{array}{l}\text { Users' "subjective norm" for using the system has } \\
\text { positive influence on "perceived usefulness" }\end{array}$ & $-0.01(-0.18)$ & Unsupported \\
\hline $\mathrm{H} 3$ & $\begin{array}{l}\text { Users' "subjective norm" for using the system has } \\
\text { positive influence on "image" }\end{array}$ & $0.39(5.43)$ & Supported \\
\hline $\mathrm{H} 4$ & $\begin{array}{l}\text { Users' "image" for using the system has positive influ- } \\
\text { ence on "perceived usefulness" }\end{array}$ & $0.02(0.33)$ & Unsupported \\
\hline H5 & $\begin{array}{l}\text { Users' "perceived usefulness" of the system has positive } \\
\text { influence on their "intention to use" the system }\end{array}$ & 0.35 (3.89) & Supported \\
\hline $\mathrm{H} 6$ & $\begin{array}{l}\text { "Job relevance" of the system has positive influence on } \\
\text { users' "perceived usefulness" of the system }\end{array}$ & $0.37(4.86)$ & Supported \\
\hline $\mathrm{H} 7$ & $\begin{array}{l}\text { "Output quality" of the system has positive influence on } \\
\text { users' "perceived usefulness" of the system }\end{array}$ & $0.27(3.42)$ & Supported \\
\hline $\mathrm{H} 8$ & $\begin{array}{l}\text { Users' "perceived ease of use" of the system has positive } \\
\text { influence on their "perceived usefulness" of the system }\end{array}$ & $0.29(3.35)$ & Supported \\
\hline H9 & $\begin{array}{l}\text { "Result demonstrability" of the system has positive } \\
\text { influence on users' "perceived usefulness" of the system }\end{array}$ & $-0.03(-0.35)$ & Unsupported \\
\hline $\mathrm{H} 10$ & $\begin{array}{l}\text { Users' "perceived ease of use" of the system has positive } \\
\text { influence on their "intention to use" the system }\end{array}$ & $0.21(1.97)$ & Supported \\
\hline
\end{tabular}

Note: The numerical figure is standardized parameter estimate, and the parenthesized value denotes the $t$-value. 
them, subjective norm had the most contribution. PEU and subjective norm also had direct impact on PU. ${ }^{47}$ Ketikidis et $\mathrm{al}^{\mathrm{s}} \mathrm{s}^{48}$ findings showed that subjective norms directly predicted HIT usage intentions. Eventually, there are few studies on the use of the TAM2 in predicting the usage behavior of HISs. In this study, the hypothesis of social influence processes influence (voluntariness, subjective norm, and image) the intention to use the system in paraclinical sections was rejected. In addition, all cognitive instrumental processes', including job relevance, output quality, result demonstrability, and PEU constructs, positive influence on the intention to use the system (except for result demonstrability) are empirically confirmed. The result shows that social influence processes do not fit well to the selected systems, and they should identify the factors affecting social influence processes.

The findings of this study showed that the training has a significant impact on the three important latent PU, job relevance, and intention to use variables $(p<0.05)$ and indirectly and directly affect the intention to use the systems. These findings are consistent with the study by Aggelidis and Chatzoglou. ${ }^{22}$ In addition, experience of using system factor has a significant impact on the PU $(p<0.05)$. A significant direct relationship was found between work experience and intention to use $(p<0.01)$. However, familiarity with IT is the most influential mediator variable that affects most of the latent variables of the model. This variable affects the PU $(p<0.01)$, PEU $(p<0.01)$, subjective norm $(p<0.05)$, image $(p<0.05)$, job relevance $(p<0.01)$, quality output $(p<0.05)$, and result demonstrability $(p<0.032)$. These results are consistent with the study by Yu et al. ${ }^{45}$ Therefore, hospitals can increase the acceptance rate and use of information systems of paraclinical departments by holding training courses and teaching IT to hospitals staffs.

According to Lehmann et al, "The technology must deliver tangible benefits to the intended end users. While benefits such as 'improving care' are laudable, end users need a clearer understanding of how the new technology will benefit them or benefit their patients in a more direct and specific fashion." ${ }^{49,50}$ In clinical departments, the impact of HISs on the customers (patients) is evident, and in addition to the system users (staffs), the customers (patients) can be considered as the end-users for meaningful use and acceptance of the system. Also, peer-peer concepts and factors can be considered. But in this study and paraclinical departments, the customers (patients) do not use the system (HIS), and thus, patients do not have an understanding of the system. In addition, in paraclinical sections such as radiology, laboratory, and nutrition, the consequences of the HIS system on the patient are subtle, and not readily understood by the patients. The impact of the HIS system in paraclinical sections on the patient is indirect, and many factors can affect the patient's understanding of the system. Predicting the use of the HIS system cannot be done just using a patient, because the results obtained from the system are affected by many other factors, including primary health groups (physicians, nurses, and other hospital staffs), and clinical system modules of the HIS system. Results obtained from paracli- nical systems, in addition to patients, are evaluated by physicians, nurses, and clinical staffs.

Finally, the ineffectiveness of result demonstrability factor on the intention to use the system can be due to the intangible benefits of HISs in paraclinical departments on improving patient care. Finding ways to deliver at least some tangible benefits to the users in this situation is necessary. Also, the mechanisms should be considered to strengthen the social impact process, because these factors are one of the most important factors affecting the intention to use the system in other health technologies. At the same time, we should not overlook other variables affecting the intention to use the system (such as training, familiarity with IT, etc.).

\section{Conclusion}

The implementation and usage of health care IT can efficiently reduce increasing health care costs and enhance health care service quality. This study made a contribution to the study of adoption of HISs by applying the TAM2. This study, conducted in Iran, offers an opportunity for countries around the world (university hospitals) to examine and develop their HIS health care technology issues. However, the TAM2 factors in clinical departments confirmed in other studies well, but the number of the studies conducted in paraclinical departments is few. The results of this study suggest that the HIS should be settled and customized considering the process and target populations of each department.

Several mediator and demographic variables in this study can be a part of the HISs acceptance model. Acceptance of HIS, especially those systems working in paraclinical departments, requires further studies. So, TAMs should be evaluated more in paraclinical departments.

The results of this study showed that cognitive instrumental processes are more important than the social influence processes in the paraclinical departments among those who use HIS. While health care systems' failures are multifactorial, the human behavioral changes in implementation and usage of hospital systems are essential for the ultimate functionality of a system, and these changes can predict the use of a system by users. Behavioral and human factors can lead to system failure if it is inconsistent with the use of the system. Also, paying attention to social and psychology factors in government-owned hospitals can influence how a system is used in hospital sections.

However, the findings provide valuable information for information systems in HIS service providers, planners, and policy makers to develop the strategies and policies for the successful implementation and acceleration of the adoption of this technology among hospitals, particularly in a developing country such as Iran.

\section{Clinical Relevance Statement}

This study enhances our understanding of important factors affecting HIS's acceptance in paraclinical departments. It provides valuable information for hospital system providers and policy makers in understanding the adoption challenges 
and also provides practical guidance for the successful implementation of these systems.

\section{Multiple Choice Questions}

1. Which processes were integrated in TAM2?

a. The social influence and the cognitive instrumental processes

b. The attitude and social norms and the perceived ease of use

c. The perceived usefulness and the behavioral intention d. The social influence and the perceived usefulness

Correct Answer: The correct answer is option a. The TAM2 incorporates additional theoretical constructs that include social influence processes (subjective norm, voluntariness, and image) and cognitive instrumental processes (job relevance, output quality, result demonstrability, and perceived ease of use).

2. Which one of the following choices has been shown in this study?

a. Cognitive instrumental processes are more important than the social influence processes.

b. The training has not a significant impact on the ease of use.

c. Experience of using the system factor has a significant impact on the ease of use.

d. A significant direct relationship was found between work experience and training.

Correct Answer: The correct answer is option a. The study showed that in the paraclinical sections, the cognitive instrumental processes is more important than the social influence processes.

\section{Protection of Human and Animal Subjects}

All procedures were approved by the Institutional Review Board at Urmia University of Medical Sciences and are in compliance with all ethical guidelines.

\section{Conflict of Interest}

None.

\section{Acknowledgments}

This work was supported by Urmia University of Medical Science. We also thank the paraclinical staffs from Urmia and Khorramabad university hospitals who provided insight and expertise that greatly assisted the research.

\section{References}

1 Scott RE. e-Records in health-preserving our future. Int J Med Inform 2007;76(5-6):427-431

2 Coiera E. Guide to Health Informatics. New York: CRC Press; 2015

3 Esmaeili M, Toloie EA, Pour EA, Rogheyeh E. Study on feasibility and acceptance of implementation of Technology Acceptance Model of Davis in staff of Shahid Beheshti University of Medical Sciences. Pajoohandeh J 2013;18(01):40-45
4 Lu Y-C, Xiao Y, Sears A, Jacko JA. A review and a framework of handheld computer adoption in healthcare. Int J Med Inform 2005;74(05):409-422

5 Ammenwerth E, Gräber S, Herrmann G, Bürkle T, König J. Evaluation of health information systems-problems and challenges. Int J Med Inform 2003;71(2-3):125-135

6 Vakilimofrad H. Hospital information system and its role in medical and health services development: a review. Pajouhan Sci J 2012;11(01):12-18

7 Ward R. The application of technology acceptance and diffusion of innovation models in healthcare informatics. Health Policy Tech 2013;2(04):222-228

8 Winter A, Reinhold H, Elske A, Birgit B, Nils H, Franziska J. Health Information Systems. London: Springer; 2010: $33-42$

9 Haux R. Health information systems - past, present, future. Int J Med Inform 2006;75(3-4):268-281

10 Wuri P, Handayani PIS, Hidayanto AN, et al. Integrated hospital information system architecture design in Indonesia. In: Tiko I, Arthur T, eds. Maximizing Healthcare Delivery and Management through Technology Integration. Hershey, PA, USA: IGI Global; 2016:207-236

11 Nadri H, Rahimi B, Timpka T, Sedghi S. The top 100 articles in the medical informatics: a bibliometric analysis. J Med Syst 2017; 41(10): 150

12 Amoako-Gyampah K, Salam AF. An extension of the technology acceptance model in an ERP implementation environment. Inf Manage 2004;41(06):731-745

13 Agarwal R, Jayesh P. The role of innovation characteristics and perceived voluntariness in the acceptance of information technologies. Decis Sci 1997;28(03):557-582

14 Zheng K, Padman R, Krackhardt D, Johnson MP, Diamond HS. Social networks and physician adoption of electronic health records: insights from an empirical study. J Am Med Inform Assoc 2010;17(03):328-336

15 Davis FD, Bagozzi RP, Warshaw PR. User acceptance of computer technology: a comparison of two theoretical models. Manage Sci 1989;35(08):982-1003

16 Venkatesh V, Davis FD. A theoretical extension of the technology acceptance model: four longitudinal field studies. Manage Sci 2000;46(02):186-204

17 Kripanont N. Examining a Technology Acceptance Model of Internet Usage by Academics within Thai Business Schools. (Doctoral dissertation); 2007. Available at: www.vuir.vu.edu.au/1512/ 1/Kripanont.pdf

18 Schierz PG, Oliver S, Wirtz BW. Understanding consumer acceptance of mobile payment services: an empirical analysis. Electron Commerce Res Appl 2010;9(03):209-216

19 D'Souza JM, Hunter I. Why should I?-acceptance of health information technology among health professionals Stud Health Technol Inform 2015;216:962

20 Handayani PW, Hidayanto AN, Pinem AA, Hapsari IC, Sandhyaduhita PI, Budi I. Acceptance model of a hospital information system. Int J Med Inform 2017;99:11-28

21 Gagnon M-P, Desmartis M, Labrecque M, et al. Systematic review of factors influencing the adoption of information and communication technologies by healthcare professionals. J Med Syst 2012;36(01):241-277

22 Aggelidis VP, Chatzoglou PD. Using a modified technology acceptance model in hospitals. Int J Med Inform 2009; 78(02):115-126

23 Lai HM. Physician Acceptance Behavior of the Electronic Medical Records Exchange: An Extended Decomposed Theory of Planned Behavior. PACIS 2013 Proceedings. 197. Available at: aisel.aisnet. org/pacis2013/197

24 Strudwick G. Predicting nurses' use of healthcare technology using the technology acceptance model: an integrative review. Comput Inform Nurs 2015;33(05):189-198 
25 Marangunić N, Andrina G. Technology acceptance model: a literature review from 1986 to 2013. Univers Access Inf Soc 2015;14(01):81-95

26 Ducey AJ, Coovert MD. Predicting tablet computer use: an extended technology acceptance model for physicians. Health Policy Tech 2016;5(03):268-284

27 Garavand A, Mohseni M, Asadi H, Etemadi M, Moradi-Joo M, Moosavi A. Factors influencing the adoption of health information technologies: a systematic review. Electron Physician 2016; 8(08):2713-2718

28 Ologeanu-Taddei R, Morquin D, Domingo H, Bourret R. 2015. Understanding the acceptance factors of an Hospital Information System: evidence from a French University Hospital. AMIA Annual Symposium Proceedings; 2015:1001-1007

29 Davis FD. Perceived usefulness, perceived ease of use, and user acceptance of information technology. Manage Inf Syst Q 1989; 13(03):319-340

30 Fishbein MA, Ajzen I. Belief, Attitude, Intention, and Behavior: An Introduction to Theory and Research. Reading, MA: AddisonWesley; 1977

31 Aversano N. Technology Rejection of Mobile Telephones. Case Western Reserve University (doctoral dissertation); 2005

32 Taylor S, Peter T. Assessing IT usage: the role of prior experience. Manage Inf Syst Q 1995;19(04):561-570

33 Pfeffer J. Organizations and Organization Theory. Boston, MA: Pitman; 1982

34 Wu M-Y, Chou H-P, Yung-Chien W, Yen-Han H. TAM-2 based study of website user behavior-using web 2.0 websites as an example. WSEAS Trans Bus Econ 2011;4(08):133-151

35 Kieras D, Polson PG. An approach to the formal analysis of user complexity. Int J Man Mach Stud 1985;22(04):365-394

36 Polson PG. Interfacing thought: cognitive aspects of humancomputer interaction. Cambridge, MA: MIT Press; 1987: 184-235

37 Hair JF, Black WC, Babin BJ, Anderson RE, Tatham RL. Multivariate Data Analysis. Upper Saddle River, NJ: Prentice Hall; 1987

38 Gold AH, Arvind M, Segars AH. Knowledge management: an organizational capabilities perspective. J Manage Inf Syst 2001; 18(01):185-214

39 Bagozzi RP, Yi Y. On the evaluation of structural equation models. J Acad Mark Sci 1988;16(01):74-94
40 Hsiao JL, Chang HC, Chen RF. A study of factors affecting acceptance of hospital information systems: a nursing perspective. J Nurs Res 2011;19(02):150-160

41 Tung F-C, Chang S-C, Chou C-M. An extension of trust and TAM model with IDT in the adoption of the electronic logistics information system in HIS in the medical industry. Int J Med Inform 2008;77(05):324-335

42 Chen R-F, Hsiao J-L. An empirical study of physicians' acceptance of hospital information systems in Taiwan. Telemed J E Health 2012;18(02):120-125

43 Asua J, Orruño E, Reviriego E, Gagnon MP. Healthcare professional acceptance of telemonitoring for chronic care patients in primary care. BMC Med Inform Decis Mak 2012;12(01):139

44 Tavakoli N, Jahanbakhsh M, Shahin A, Mokhtari H, Rafiei M. Electronic medical record in central polyclinic of Isfahan oil industry: a case study based on technology acceptance model. Acta Inform Med 2013;21(01):23-25

$45 \mathrm{Yu}$ P, Li H, Gagnon MP. Health IT acceptance factors in long-term care facilities: a cross-sectional survey. Int J Med Inform 2009; 78(04):219-229

46 Huang J-C. Innovative health care delivery system-a questionnaire survey to evaluate the influence of behavioral factors on individuals' acceptance of telecare. Comput Biol Med 2013; 43(04):281-286

$47 \mathrm{Wu}$ J-H, Shen W-S, Lin L-M, Greenes RA, Bates DW. Testing the technology acceptance model for evaluating healthcare professionals' intention to use an adverse event reporting system. Int J Qual Health Care 2008;20(02):123-129

48 Ketikidis P, Dimitrovski T, Lazuras L, Bath PA. Acceptance of health information technology in health professionals: an application of the revised technology acceptance model. Health Informatics J 2012;18(02):124-134

49 Lehmann CU, Unertl KM, John RM, Lorenzi NM. Change management for the successful adoption of clinical information systems. In: Finnell JT, Dixon BE, eds. Clinical Informatics Study Guide: Text and Review. Cham: Springer International Publishing; 2016: 435-456

50 Maillet É, Mathieu L, Sicotte C. Modeling factors explaining the acceptance, actual use and satisfaction of nurses using an Electronic Patient Record in acute care settings: an extension of the UTAUT. Int J Med Inform 2015;84(01):36-47 